Surgery for

Congenital Heart

Disease

\title{
Primary repair of pulmonary atresia with ventricular septal defect and major aortopulmonary collaterals: A useful approach
}

Raul F. Abella, MD

Teresa De la Torre, $\mathrm{MD}^{\mathrm{a}}$

Gerardo Mastropietro, CCP

Nuccia Morici, MD

Adriano Cipriani, $\mathrm{MD}^{\mathrm{b}}$

Carlo Marcelletti, MD

From the Division of Cardiovascular Surgery, Hospital San Donato, ${ }^{a}$ San Donato Milanese, Italy, and Division of Cardiovascular Surgery, Hospital Civico of Palermo, ${ }^{\text {b }}$ Palermo, Italy.

Received for publication Aug 29, 2002; revisions requested Nov 5, 2002; revisions received Nov 19, 2002; accepted for publication Dec 2, 2002.

Address for reprints: Dr Abella, Divisione di Cardiochirurgia I, Istituto Policlinico San Donato, Via Morandi 30, 20097 San Donato Milanese, Italy (E-mail: r_abella@hotmail.com).

J Thorac Cardiovasc Surg 2004;127: 193-202

$0022-5223 / \$ 30.00$

Copyright $\odot 2004$ by The American Association for Thoracic Surgery

doi:10.1016/S0022-5223(03)00091-6

Background: The ultimate goal of surgical therapy for pulmonary atresia with ventricular septal defect and major aortopulmonary collateral arteries is to create unobstructed and separate in series pulmonary and systemic circuits. Our preference has been a 1-stage complete unifocalization technique, avoiding collateral anastomosis with either the native pulmonary arteries or other aortopulmonary collateral vessels.

Methods and Results: Since 1998, 5 patients (median age 29.6 months) with pulmonary atresia, ventricular septal defect, and major aortopulmonary collateral arteries have undergone surgical correction, consisting of (1) exclusion of a descending thoracic aortic segment from which all major aortopulmonary collateral arteries originate, and (2) connection of this aortic segment to the native pulmonary artery using an interposition polytetrafluoroethylene conduit. The ventricular septal defect was closed in all patients, and the right ventricle was connected to the unifocalized pulmonary artery with a valved conduit. All patients survived the operation. Two patients required reexploration for postoperative bleeding. One patient remained on mechanical ventilation for 17 days due to a pulmonary infection. During follow-up (12-21 months), no patient required additional interventions. The postoperative right ventricular/left ventricular pressure ratio was 0.55 median. No significant stenosis within the reconstructed pulmonary circuit was identified. All patients remain free of symptoms, requiring no medications.

Conclusion: Intracardiac repair of pulmonary atresia with ventricular septal defect and major aortopulmonary collateral arteries can be accomplished by a midline 1-stage repair including complete unifocalization of all pulmonary blood supply without individual collateral anastomosis in selected patients. This approach offers a convenient and satisfactory surgical option.

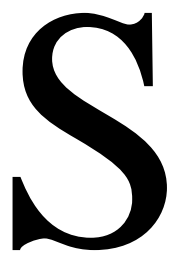

urgery for pulmonary atresia (PA) with ventricular septal defect (VSD) and major aortopulmonary collateral arteries (MAPCAs) has evolved significantly during the past decade. The ultimate goal of surgical therapy in this lesion is to create unobstructed and separate in series pulmonary and systemic circuits.

An important physiologic factor that signifies a favorable outcome for these patients is postrepair peak right ventricular pressure, which indirectly reflects both 
TABLE 1. Clinical patient data: Single-stage unifocalization

\begin{tabular}{ccccccc}
\hline Patient & $\begin{array}{c}\text { Age at } \\
\text { repair (mo) }\end{array}$ & $\begin{array}{c}\text { Weight } \\
(\mathbf{k g})\end{array}$ & Diagnosis & $\begin{array}{c}\text { Previous palliative } \\
\text { operations }\end{array}$ & $\begin{array}{c}\text { Age } \\
\text { (mo) }\end{array}$ & \begin{tabular}{c} 
Saturation Ao (\%) \\
\hline 1
\end{tabular} \\
5 & 6.1 & PA, VSD, MAPCAs \#3 & - & 96 \\
2 & 22 & 11 & PA, VSD, MAPCAs \#4 & Outflow patch RV-PA & 8 \\
3 & 29 & 11.5 & PA, VSD, MAPCAs \#3 & Outflow patch RV-PA & 13 & 98 \\
4 & 48 & 15 & PA, VSD, MAPCAs \#4 & - & 90 \\
5 & 55 & 12 & PA, VSD, MAPCAs \#3 & - & 98 \\
\hline
\end{tabular}

Ao, Aorta; $P A$, pulmonary atresia; $V S D$, ventricular septal defect; MAPCAs, major aortopulmonary collateral arteries; RV, right ventricular; $P A s$, pulmonary arteries.

the number of lung segments incorporated by unifocalization and the status of the pulmonary microvasculature within those segments. ${ }^{1,2}$

According to Reddy and colleagues, ${ }^{3}$ early 1 -stage complete unifocalization offers the best chance of achieving most or all of these goals. Although early and intermediate survival has indeed been favorable with this treatment philosophy, the need for late reinterventions on the reconstructed pulmonary arteries has been disappointing, unfortunately.

Therefore, we have recently adopted a 1-stage complete unifocalization technique that eliminates the need for anastomosis of individual aortopulmonary collateral vessels. We present our experience with this approach in the first 5 patients.

\section{Methods}

Between December 1998 and April 2000, 5 patients with PA, VSD, and MAPCAs underwent 1-stage repair consisting of (1) exclusion of the descending thoracic aortic segment containing the origin of all MAPCAs and (2) connection of this aortic segment to the native pulmonary artery with an interposition polytetrafluoroethylene (PTFE) conduit, thus eliminating the need for multiple anastomoses to either other aortopulmonary collaterals or to native pulmonary arteries. In addition, the VSD was closed and the right ventricle was connected to unifocalized pulmonary arteries using a valved conduit. Four patients were male and 1 was female. Median age at surgery was 29.6 months (range 5-55 months). Two of the patients had been subjected to a palliative right ventricular outflow tract reconstruction 13 and 16 months before the definitive repair (patients 2 and 3; Table 1). ${ }^{4}$ All patients underwent 2-dimensional echocardiography. An effort was made in all patients to identify at cardiac catheterization the central and peripheral native pulmonary arteries and also the hemodynamics and morphologic characteristics of the major aortopulmonary collaterals (Figure 1).

The morphologic characteristics of the MAPCAs and of the true pulmonary arteries are detailed in Tables 2 and 3. All MAPCAs were identified by selective injections and their origin, course, distribution, and presence of stenosis defined as clearly as possible. The central pulmonary arteries were preoperatively identified either by cineangiograms after right ventricular injections or retrograde filling of MAPCAs injection or by retrograde pulmonary venous wedge injections. The size of the true pulmonary arteries was measured just before their bifurcation, as described by Nakata and associates. ${ }^{5}$

All patients had a single malalignment type VSD.

\section{Surgical Technique}

The mediastinum was entered through median sternotomy and a transsternal thoracotomy ipsilateral to the aortic arch. The pleural spaces were opened wide anterior to both phrenic nerves, and the lungs were partially lifted out of the pleural cavities. The descending aorta was dissected free in the posterior mediastinum; the origins of the MAPCAs were identified, dissected looped, and temporarily occluded during bypass. Cardiopulmonary bypass was established by means of aorta-bicaval cannulation and a left atrial vent. While the patient was cooled to $18^{\circ} \mathrm{C}$, the lungs were continuously ventilated. The ascending aorta was crossclamped and blood cardioplegia was administered. A short period of cardiac arrest was used for transsection of the descending aortic segment containing the origins of all aortopulmonary collateral vessels. Continuity of the descending thoracic aorta was established by interposing a $10-\mathrm{mm}$ PTFE conduit in 2 patients and a $12-\mathrm{mm}$ conduit in 2 patients. A direct end-to-end anastomosis of the thoracic aorta was possible in 1 patient (Table 4 and Figure 2, A and $B$ ). The resected aortic segment containing all MAPCAs measured approximately $5 \mathrm{~cm}$ in all 5 patients. The excised descending aortic segment was sutured distally, and the proximal stoma was anastomosed to the native pulmonary artery with a 16-mm PTFE conduit in 3 patients, a 14-mm conduit in 1 , and a 12-mm conduit in the fifth patient (Table 4 and Figure $3, A$ and $B$ ). At this point, cardiopulmonary bypass was restarted, and the intracardiac repair was carried out.

\section{Intracardiac Repair}

The right ventricle was entered though a longitudinal incision limited to the right ventricular outflow tract. The VSD was closed with a PTFE patch in all patients. In 2 patients, an interatrial communication was only partially closed to allow for postoperative decompression of the right side of the heart.

The aortic crossclamp was then released, and during rewarming a 16-mm porcine bioprosthetic valved conduit (Hancock; Medtronic, Inc, Minneapolis, Minn) was used in 3 patients and heterologous (bovine) valved conduits (VenPro, Irvine, Calif) in 2 patients $(12 \mathrm{~mm}$ and $14 \mathrm{~mm})$ to connect the right ventricle to the reconstructed neopulmonary arterial system (Table 4 and Figure 4, $A$ and $B$ ). Median duration of cardiopulmonary bypass was 220 


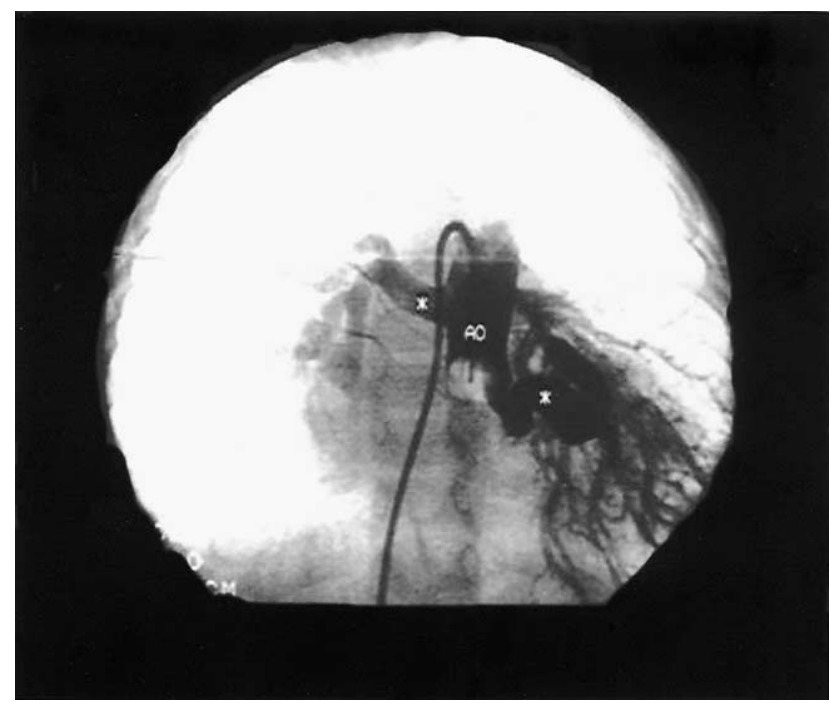

Figure 1. Preoperative descending aortoangiogram demonstrating systemic collaterals in case 4 (a patient with pulmonary atresia, ventricular septal defect, and small central pulmonary arteries).

TABLE 2. Total number and distribution of mapcas

\begin{tabular}{|c|c|c|c|}
\hline \multicolumn{2}{|c|}{$\begin{array}{l}\text { No. collateral to each } \\
\text { lung }\end{array}$} & \multicolumn{2}{|c|}{ Lobar distribution of MAPCAs } \\
\hline Right & Left & Right & Left \\
\hline 2 & 1 & $\begin{array}{l}\text { UL } 1 \\
\text { ML } 2 \\
\text { LL } 5\end{array}$ & UL 2 \\
\hline 3 & 1 & $\begin{array}{l}\text { UL } 1 \\
\text { ML } 2 \\
\text { LL } 2\end{array}$ & $\begin{array}{l}\text { LL } 3 \\
\text { Lingula } 2\end{array}$ \\
\hline 1 & 2 & $\begin{array}{l}\text { UL } 3 \\
\text { ML } 2\end{array}$ & $\begin{array}{l}\text { UL } 2 \\
\text { LL } 5\end{array}$ \\
\hline 1 & 2 & LL 5 & $\begin{array}{l}\text { Lingula } 2 \\
\text { LL } 5\end{array}$ \\
\hline 2 & 2 & $\begin{array}{l}\text { UL } 2 \\
\text { LL } 3\end{array}$ & $\begin{array}{l}\text { UL } 3 \\
\text { LL } 2\end{array}$ \\
\hline
\end{tabular}

$U L$, Upper lobe; $M L$, middle lobe; $L L$, lower lobe.

minutes (range 120-305 minutes). Average cardioplegic arrest time was 70 minutes (range 52-87 minutes). Median duration of circulatory arrest was 49 minutes (range 49-66 minutes). After weaning from cardiopulmonary bypass, right ventricular, pulmonary arterial, and left atrial pressures were measured continuously. An intraoperative transesophageal echocardiogram was obtained to ensure that there were no significant residual defects.

Bilateral pleural and mediastinal tube drains were placed, and the sternum was electively left open in all patients.

\section{Results}

All 5 patients survived the operation. All VSDs were successfully closed.

Two patients required reexploration for postoperative bleeding from the interposition descending thoracic aortic
TABLE 3. Pulmonary artery morphology

\begin{tabular}{cccc}
\hline & & \multicolumn{2}{c}{$\begin{array}{c}\text { No. of lung segments } \\
\text { supplied by PAs }\end{array}$} \\
\cline { 3 - 4 } Patient & $\begin{array}{c}\text { Nakata index } \\
\left(\mathbf{m m}^{\mathbf{2}} / \mathbf{m}^{\mathbf{2}}\right)\end{array}$ & Right & Left \\
\hline 1 & 127 & 2 & 8 \\
2 & 204 & 5 & 5 \\
3 & 112 & 5 & 3 \\
4 & 168 & 5 & 3 \\
5 & 133 & 5 & 5
\end{tabular}

PAs, Pulmonary arteries.

TABLE 4. Descending thoracic aortic reconstruction and method of right ventricular-pulmonary artery reconstruction

\begin{tabular}{cccc}
\hline Patient & $\begin{array}{c}\text { Descending aorta } \\
\text { reconstruction }\end{array}$ & $\begin{array}{c}\text { Ao-PA } \\
\text { conduit } \\
(\mathbf{m m})\end{array}$ & $\begin{array}{c}\text { Valved RV-PA } \\
\text { conduit (mm) }\end{array}$ \\
\hline 1 & $\begin{array}{c}\text { End-to-end anastomosis } \\
10 \text { mm PTFE conduit } \\
\text { interposition }\end{array}$ & $\begin{array}{c}\text { PTFE12 } \\
\text { PTFE14 }\end{array}$ & $\begin{array}{c}\text { VenPro, 12 E-S } \\
\text { Hancock, 16 E-S }\end{array}$ \\
3 & $\begin{array}{c}10 \text { mm PTFE conduit } \\
\text { interposition }\end{array}$ & PTFE16 & Hancock, 16 E-S \\
4 & $\begin{array}{c}12 \text { mm PTFE conduit } \\
\text { interposition }\end{array}$ & PTFE16 & VenPro, 14 E-S \\
5 & $\begin{array}{c}12 \text { mm PTFE conduit } \\
\text { interposition }\end{array}$ & PTFE16 & Hancock, 16 E-S \\
& & & \\
&
\end{tabular}

Ao, Aorta; $R V$, right ventricle; $V S D$, ventricular septal defect; $P A$, pulmonary artery; $E$-S, end-to-side anastomosis; Ao-PA conduit, interposition PTFE conduit connected to the descending thoracic aortic segment contained the origin of all MAPCAs to the pulmonary confluence; PTFE conduit, polytetrafluoroethylene tube graft; Hancock valved woven conduit, lowporosity conduit containing a porcine valve-preserved glutaraldehyde VenPro conduit with a bioprosthesis of heterologous (bovine) jugular vein including a trileaflet venous valve.

PTFE conduit. The open sternotomy incision was closed within an average of 3 days (range 1-4 days).

Postoperative mechanical ventilatory support was required for an average of 5 days (range 3-17 days). One patient required mechanical ventilation for 17 days due to a Pseudomonas pneumonia. Dopamine (3-10 $\gamma \cdot \mathrm{kg}^{-1}$. $\min ^{-1}$ ) was prescribed in the postoperative period for an average of 5 days. In addition, 2 patients required adrenaline $\left(0.05 \gamma \cdot \mathrm{kg}^{-1} \cdot \mathrm{min}^{-1}\right)$ on the first postoperative day for hemodynamic instability. One patient underwent cardiac catheterization 15 days after the unifocalization because of persistent hypoxic spells (saturation 85\%). This study confirmed a satisfactory hemodynamic repair. The right ventricular/left ventricular pressure ratio was less than 0.6, and the reconstructed pulmonary circulation was free of stenosis. The hypoxic spells in this patient eventually resolved. Postoperative complications included bronchopneumonia in 1 , prolonged episodes of bronchospasm in 1, bleeding in 2, 

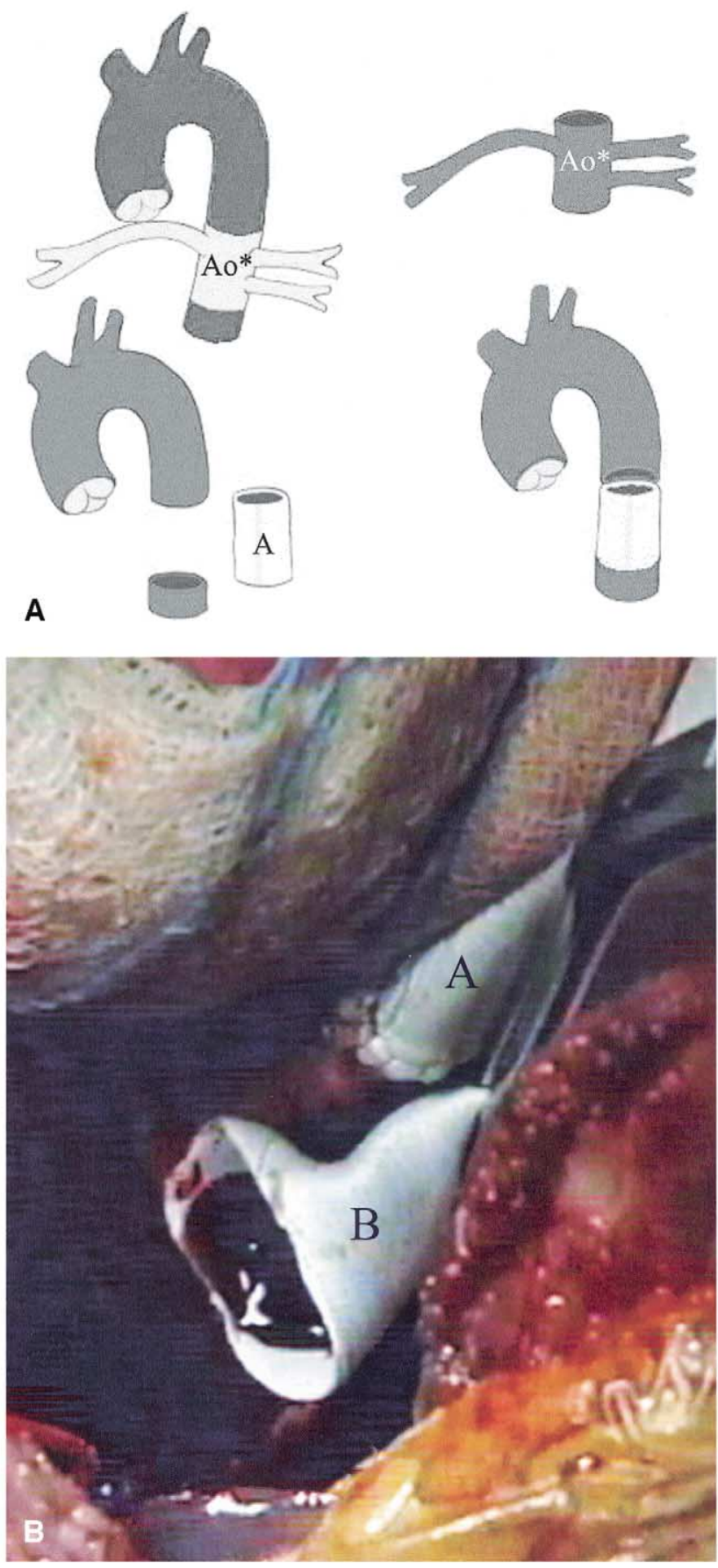

Figure 2. A, Descending thoracic aortic reconstruction. Ao*, Descending aortic segment plus collaterals; $A$, PTFE conduit. B, Operative photograph of descending thoracic aortic reconstruction. A, PTFE conduit; $B$, PTFE conduit that connects aortic segment to the native pulmonary artery.

and pleural effusion in 1. Third-degree atrioventricular block developed in 1 patient, which reverted to normal atrioventricular conduction on the 20th postoperative day.
The average stay in the intensive care unit was 10 days (range 5-25 days). Time to hospital discharge averaged 20 days (range 15-59 days).

A predischarge echocardiogram in all 5 patients revealed good right ventricular function; tricuspid regurgitation was moderate in 2 patients. All valved conduits, as well as the aortic conduits, were free of stenosis. There were also no other residual intracardiac defects. At discharge, in all patients the arterial oxygen saturations ranged from $95 \%$ to 100\% (median 98\%).

Clinical follow-up ranging from 12 to 21 months (median interval of 15.4 months) revealed that all patients were doing well and so far none required additional interventions.

Twelve months after repair, all patients underwent 2-dimensional echocardiography and cardiac catheterization to evaluate the new pulmonary circulation (Table 5).

All patients had suitable distribution of the pulmonary blood supply, and all of the pulmonary segments were adequately perfused (Figures 5 and 6). A total of 17 aortopulmonary collateral vessels were unifocalized in the 5 patients (100\%); none showed any stenosis, kinking, or obstructions at 1-year postoperative catheterization.

Right ventricular function was adequate in all; the median pulmonary artery pressure was $19 \mathrm{~mm} \mathrm{Hg}$ (range 15-24 $\mathrm{mm} \mathrm{Hg}$ ). In 4 patients the median right ventricular/left ventricular pressure ratio was 0.55 (range 0.5-0.75); the third patient (number 3 ) had a ratio of 0.75 with a peak right ventricular pressure of $50 \mathrm{~mm} \mathrm{Hg}$. This patient had a Nakata index of $112 \mathrm{~mm}^{2} / \mathrm{m}^{2}$ with a left pulmonary artery stenosis at its origin. This pulmonary artery was enlarged with a PTFE patch during unifocalization and the stenosis was resolved; this patient presumably has mild obstructive pulmonary vascular disease.

The neo-pulmonary confluence created by anastomosis of both conduits, the valved conduit from the right ventricle, and the PTFE conduit from the descending thoracic aortic to the native pulmonary artery was without significant gradient in all 5 patients.

The descending thoracic aortic reconstruction was free of stenosis in all patients. In 1 patient (patient 4) a $15 \mathrm{~mm} \mathrm{Hg}$ gradient was measured across the PTFE conduit, which seemed clinically insignificant (Figure 7).

Technetium $\left(\mathrm{Tc}^{99 \mathrm{~m}}\right)$ lung perfusion scans in 3 patients 1 year after the operation showed uniform perfusion of all pulmonary segments (Figure 8 ).

All patients are also being followed up in the outpatient clinic by echocardiography. Now, 2 years after the operation, all 5 patients are in good condition, continue to do well clinically, and remain without medications.

\section{Discussion}

The essential problem of patients with PA, VSD, and MAPCAs is an inadequate supply of native central and 


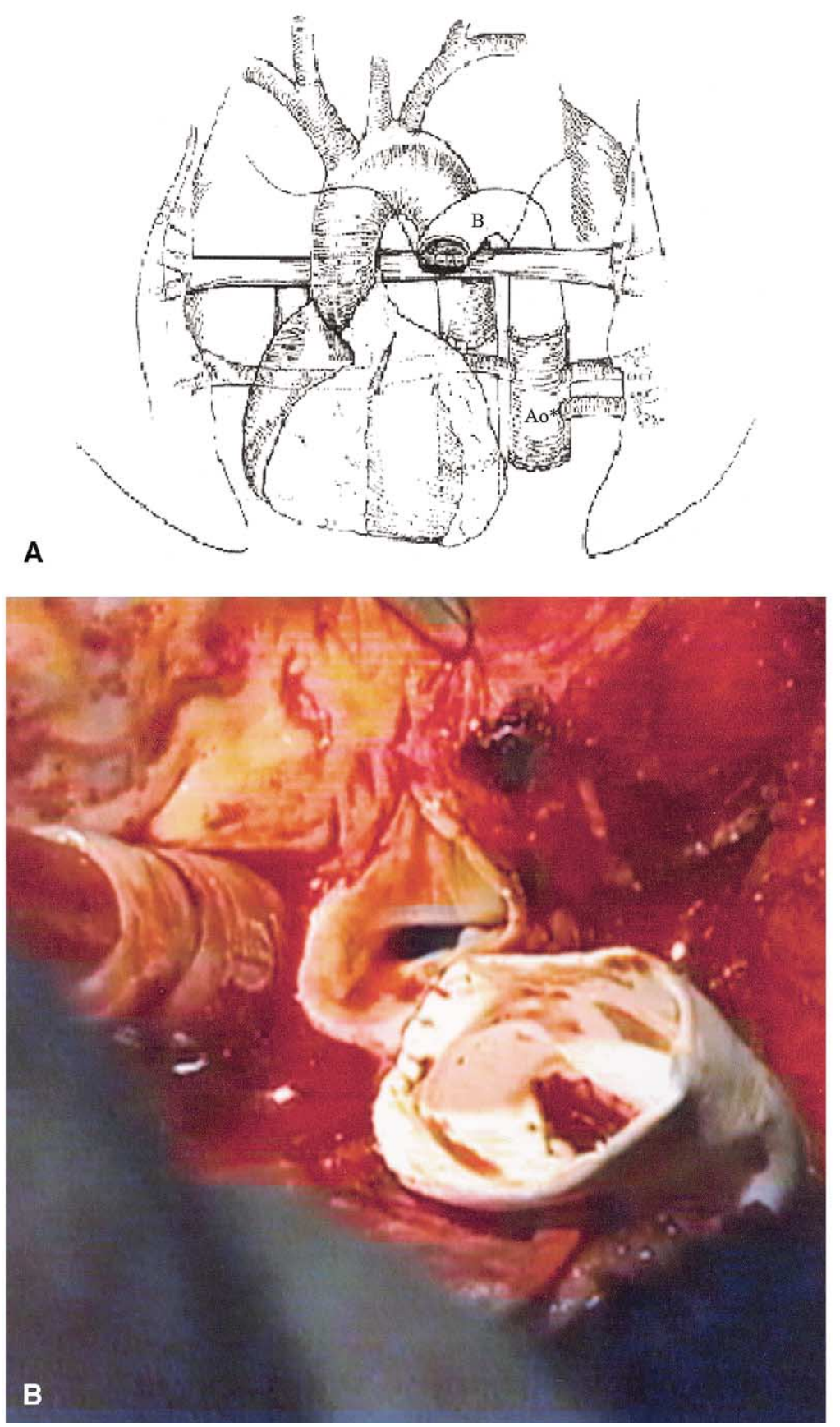

Figure 3. Diagram (A) and operative photograph (B) of connection of the descending thoracic aortic segment containing the origin of all MAPCAs to the native pulmonary artery using an interposition PTFE conduit. $B$, PTFE conduit; $A_{0} *$, descending aortic segment plus collaterals.

peripheral pulmonary arteries, with the greater part of the pulmonary parenchyma being supplied by MAPCAs. The diverse sources of pulmonary blood supply and their morphologic and hemodynamic characteristics significantly complicate management of these lesions. ${ }^{6,7}$ After systematic hemodynamic, macroscopic, and histologic studies of the aortopulmonary collateral vessels by many researchers, ${ }^{8-16}$ the concept evolved that these systemic collateral arteries could function as true pulmonary arteries if connected to the right ventricle, provided they had not undergone significant pulmonary vascular obstructive changes. 
A
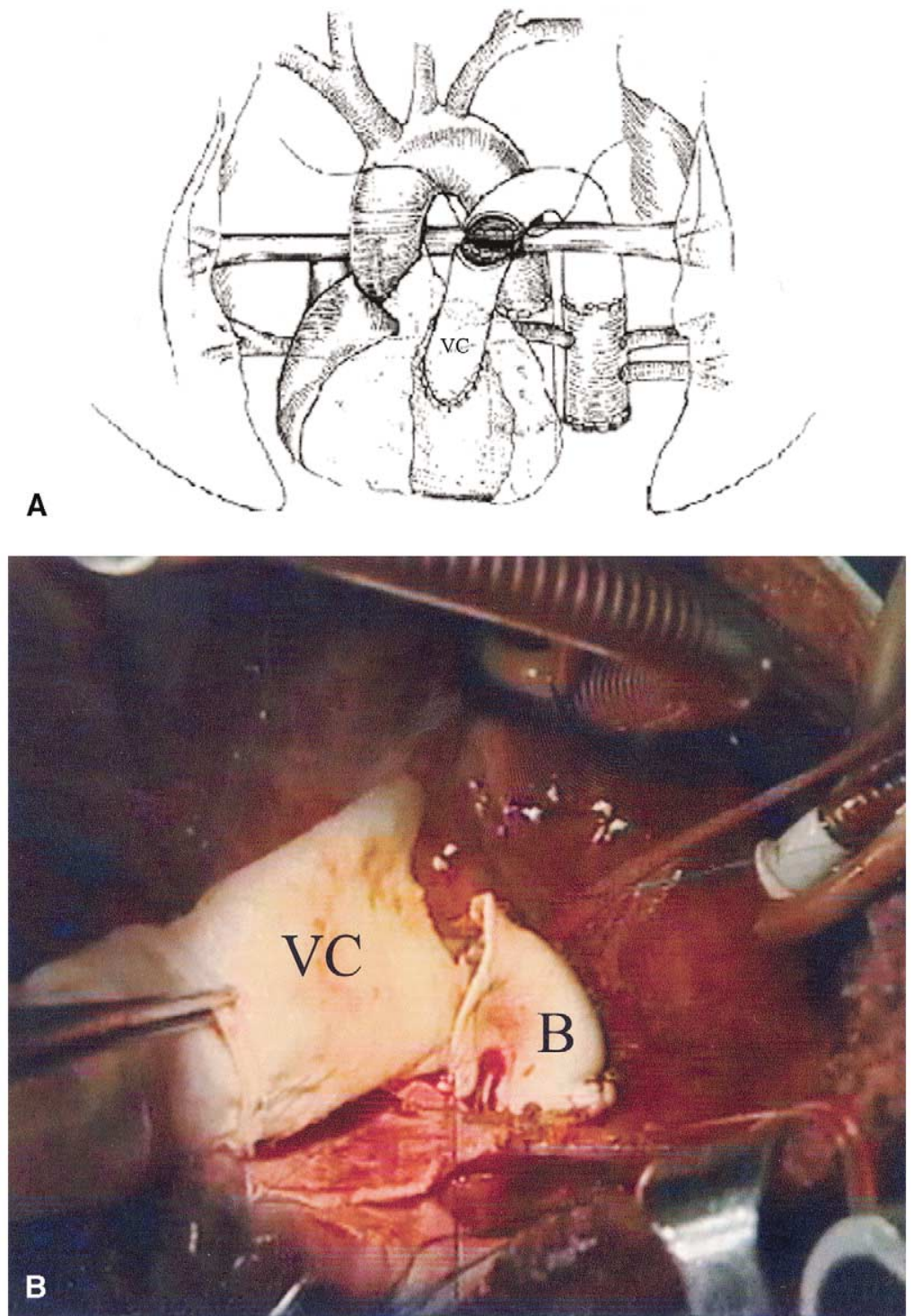

Figure 4. Diagram (A) and operative photograph (B) of connection of the right ventricle to the unifocalized pulmonary arteries using a valved conduit, creating the neo-pulmonary confluence. VC, Valved conduit; $B$, PTFE conduit connection of aortic segment to the native pulmonary artery.

Since the concept of unifocalization of pulmonary collaterals as a preliminary step to repair in patients with PA, VSD, and MAPCAs was introduced by Haworth and Macartney ${ }^{12}$ in 1980, multiple-stage procedures have been proposed by various authors ${ }^{17-22}$ to repair these complex lesions. Puga and colleagues ${ }^{18}$ reported on 38 consecutive patients; Iyer and Mee ${ }^{19}$ described their experience with 58 patients over a 10-year period; and Sawatari and cowork$\mathrm{ers}^{20}$ reviewed the results with 16 patients over a 6-year period. In general, the results of the majority of these multistage approaches were disappointing, mostly because of a high late morbidity and mortality.
Furthermore, most centers using the multistage approach excluded the very young child mostly because of the small size and the need for prosthetic grafts. In older patients, whenever direct vascular anastomosis was not possible, prosthetic grafts were used quite liberally. Unfortunately, late stenosis of these anastomoses of prosthetic grafts to small pulmonary arteries occurred quite frequently. Also, systemic arterial collaterals exposed to longer periods of systemic pressure-increased flow and shear stress tend to develop myointimal hyperplasia, leading eventually to irreversible pulmonary vascular obstructive lesions. 


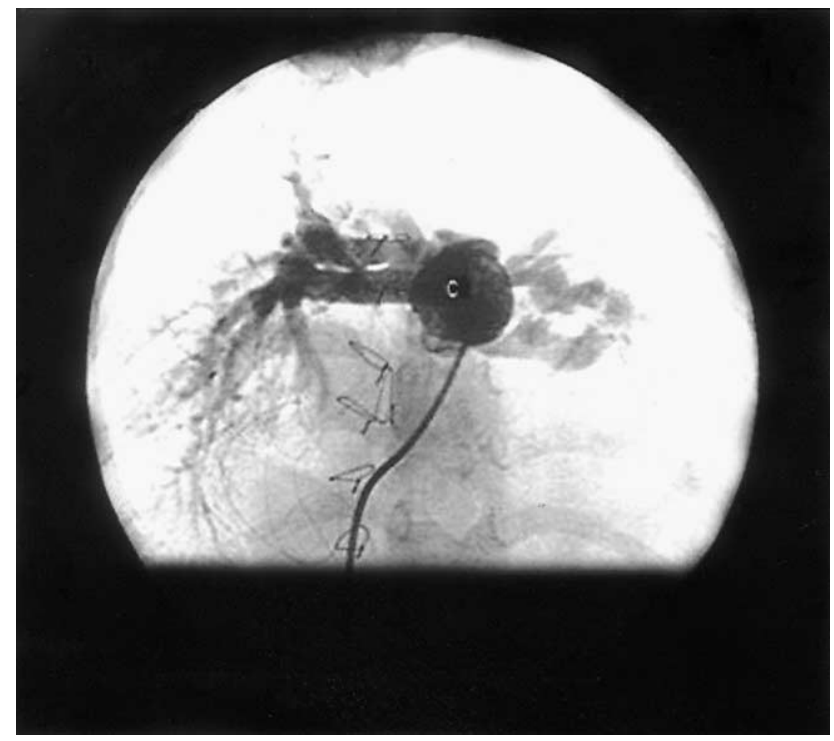

Figure 5. Postoperative angiogram for primary unifocalization procedure in case 4. Angiographic evidence of unifocalized pulmonary arterial tree. $C$, valved conduit.

The concept of using the descending aortic segment containing the origins of aortopulmonary collateral vessel to incorporate in the pulmonary circulation without MAPCAs anastomosis has been proposed previously by several authors. ${ }^{23,24}$ Murphy and colleagues ${ }^{24}$, in 1978, reported on a patient (3 years 6 months old) with PA, VSD, and MAPCAs: the descending aorta just distal to the 3 major pulmonary collaterals was ligated, and the proximal stoma was anastomosed to the right ventricle with a valved conduit (18-mm conduit; Edwards Lifesciences, Irvine, Calif). The VSD was closed. In this technique the pulmonary arterial circulation was supplied only by MAPCAs. Results of this approach were not encouraging. This procedure was abandoned.

More recently, Reddy and colleagues ${ }^{1}$ introduced an aggressive and very appealing new approach consisting of very early (young infants) single-stage unifocalization and repair. This radical approach offers the theoretical advantages of (1) establishing a normal cardiovascular physiology early in life, (2) eliminating the need for systemic-pulmonary artery shunts, (3) use of prosthetic materials, and (4) decreasing the number of required operations. Furthermore, it should also protect against the development of pulmonary vascular obstructive lesions, whether through collaterals or systemic shunts. It remains to be seen whether the natural tendency of late collateral stenosis may be averted by early normalization of hemodynamics. ${ }^{1}$ Several other centers have recently reported results with their initial experiences with 1-stage unifocalization. ${ }^{2-25}$

In 2000 , Reddy and colleagues ${ }^{3}$ reported a $10.6 \%$ early mortality and an $80 \% 3$-year survival in an initial group of

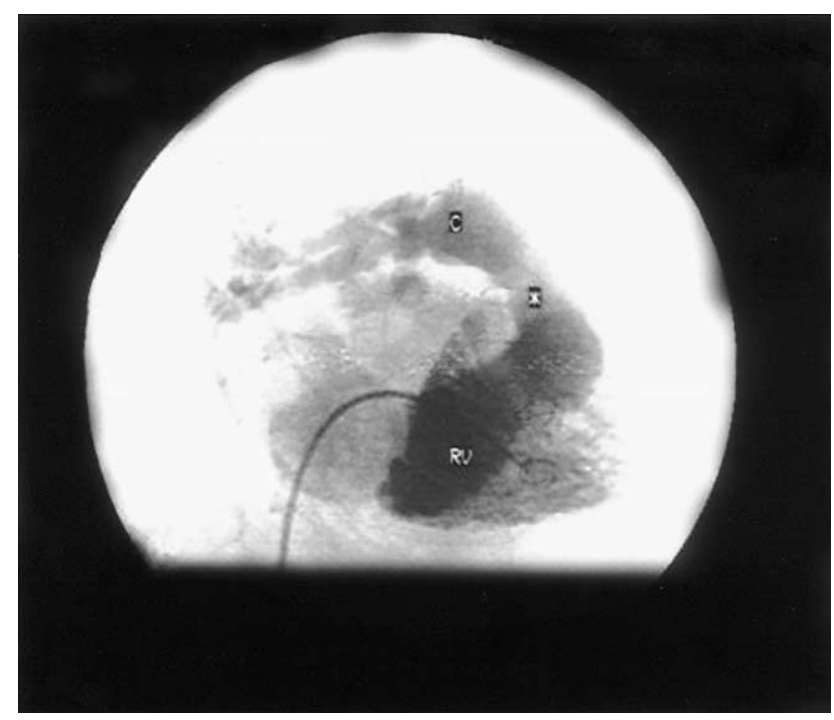

Figure 6. Postoperative right ventricular angiogram after unifocalization procedure. $C$, pulmonary confluent; white asterisks, valved conduit; $R V$, right ventricle.

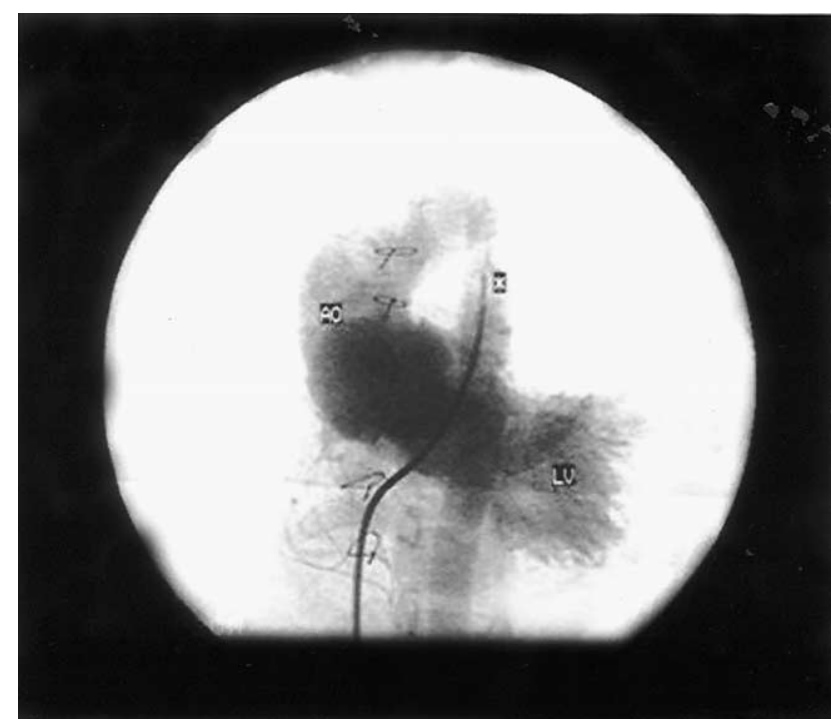

Figure 7. Postoperative angiogram demonstrating descending thoracic aortic reconstruction after unifocalization procedure. Ao, Aorta; LV, left ventricle; asterisk, descending thoracic aorta.

89 patients. Considering the complexities of this lesion, the early and intermediate survival was indeed impressive. However, it was disappointing that 24 of the surviving patients required 36 reinterventions on the unifocalized pulmonary arteries; hence, intervention-free survival was only $42 \%$ at 5 years. ${ }^{3}$

In the 1-stage early unifocalization technique, emphasis is placed on avoiding the use of synthetic or allograft 


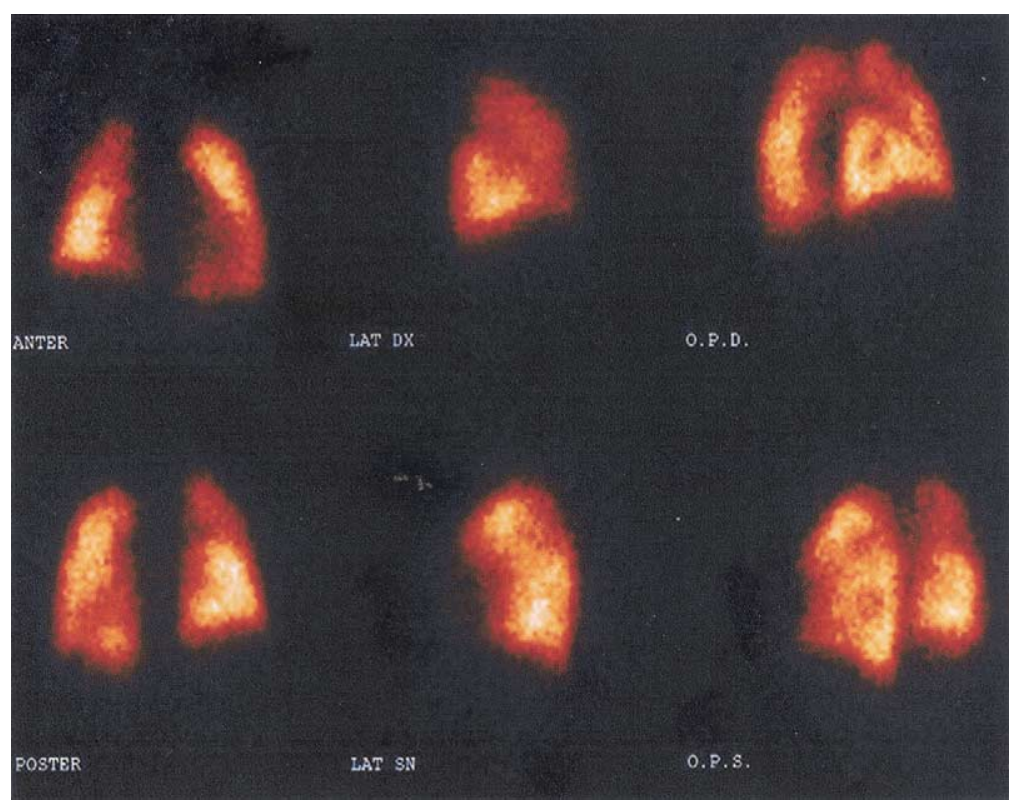

Figure 8. Postoperative $\mathrm{Tc}^{99 \mathrm{~m}}$ lung perfusion scans demonstrate perfusion of both lungs in patient 2. DX, Right; OPD, oblique posterior right; SN, left; OPS, oblique posterior left.

TABLE 5. Postoperative catheterization studies

\begin{tabular}{|c|c|c|c|c|c|c|c|c|c|}
\hline $\begin{array}{l}\text { Patient } \\
\text { No. }\end{array}$ & $\begin{array}{c}\text { Postoperative } \\
\text { (mo) }\end{array}$ & $\begin{array}{l}\text { Number of } \\
\text { MAPCAs } \\
\text { unifocalized }\end{array}$ & $\begin{array}{l}\text { Number of } \\
\text { pulmonary } \\
\text { segments } \\
\text { perfused }\end{array}$ & $\begin{array}{l}\text { PAP mean } \\
(\mathrm{mm} \mathrm{Hg})\end{array}$ & $\mathrm{pRV} / \mathrm{pLV}$ & Op/0s & $\begin{array}{c}\text { Pulmonary } \\
\text { conduit } \Delta \mathrm{P} \\
(\mathrm{mm} \mathrm{Hg})\end{array}$ & $\begin{array}{c}\text { Saturation } \\
\text { Ao }(\%)\end{array}$ & $\begin{array}{c}\text { Descending Aortic } \\
\text { conduit } \Delta \\
\text { gradient }(\mathrm{mm} \mathrm{Hg})\end{array}$ \\
\hline 1 & 12 & 3 & 20 & 15 & 0.55 & $1: 1$ & 20 & 97 & 4 \\
\hline 2 & 21 & 4 & 20 & 17 & 0.50 & 1:1 & 15 & 99 & 7 \\
\hline 3 & 13 & 3 & 20 & 24 & 0.75 & 1:1 & 26 & 96 & 8 \\
\hline 4 & 18 & 4 & 20 & 17 & 0.6 & $1: 1$ & 25 & 99 & 15 \\
\hline 5 & 13 & 3 & 20 & 22 & 0.5 & $1: 1$ & 18 & 95 & 10 \\
\hline
\end{tabular}

$p R V / p L V$, Right ventricular/left ventricular pressure ratio; $Q p Q s$, pulmonary/systemic flow ratio; $A o$, aorta; $P A P$, pulmonary artery pressure.

conduits, insisting on native tissue-to-tissue anastomosis. In neonates, surgical exposure, mobilization, and anastomosis of these collateral vessels and their corresponding pulmonary arteries can prove technically quite demanding, which could also introduce some additional technical factors that contribute to the need for late reinterventions.

Unfortunately, both the multistage or the early 1-stage unifocalization approaches have not proven entirely satisfactory.

The major advantage of the technique used in our 5 patients is the avoidance of small-vessel anastomosis, which should theoretically avoid late stenosis of either the native pulmonary arteries or of the MAPCAs.

Also, by early exposure of all aortopulmonary collaterals to a normal pulmonary artery pressure and flow, one should (theoretically) be able to anticipate avoidance of late intimal and medial pulmonary vascular pathologic changes.
Understanding of the pathophysiologic of these collateral arteries is increasing. ${ }^{6,10-12}$ Pulsatile stress and hypoxia and hyperoxia seem to first cause disruption of the elastic lamina and smooth muscle cell migration, which eventually leads to obstruction. ${ }^{26}$ According to Rabinovitch, ${ }^{27}$ the pathology of the narrowed collateral arteries resembles that of a normally closing ductus arteriosus. On the basis of these and other considerations, it seems that collateral artery disease is primarily a hemodynamic consequence rather than an intrinsic tendency of collateral vessels. ${ }^{27}$

Another important issue relates to the origins of MAPCAs in this disease. The great majority of the MAPCAs seem to originate from the descending thoracic aorta, usually in the vicinity of the left main bronchus (left aortic arch) or close to the carina in the case of a right aortic arch. ${ }^{14,22,28}$ In fewer cases, the MAPCAs can originate from a common aortic trunk arising from the ascending thoracic 
aorta; occasionally, a large left or right MAPCA may cross over to the contralateral lung. ${ }^{29}$ Finally, MAPCAs can also originate from branches of the aorta (indirect origin) such as the left or right subclavian or internal thoracic arteries or, more rarely, even from the abdominal aorta or 1 of its branches. Obviously, in these circumstances the aortic segment technique is not applicable.

The need to use prosthetic grafts in these patients with the possibility of developing stenosis remains a worrisome feature of this approach. Management of this late complication could involve reoperation in several patients. At present, procedures are undergoing with optimal results, but undoubtedly this complication may increase the morbidity in this cohort of patients in the future.

This aortic segment technique in our limited experience should be used in patients without collateral stenosis and MAPCAs originating from the descending thoracic aorta. Certainly, our selected cohort is not representative of the overall population of individuals born with this anomaly. The use of this approach combined with direct tissue-totissue anastomoses in selected patients or the help of catheter interventional techniques (balloon dilatation stenting or both) could (theoretically) be the solution to widespread application of this technique and could attempt to decrease the age of elective repair.

Clearly, the follow-up period of 12 to 21 months is too short a time span to permit a final judgment concerning the long-term fate of the unifocalized collaterals.

\section{Limitations of this Study}

More patients and a longer follow-up period are necessary to allow more definitive conclusions about the aortic segment technique.

\section{Conclusions}

Complete unifocalization of all MAPCAs and intracardiac repair of PA with VSD can be accomplished successfully, at low risk, in the presence of MAPCAs originating from the descending thoracic aorta.

This approach offers a convenient surgical option in selected patients, providing a low early risk and optimal intermediate results.

We are grateful to Professor Aldo Castañeda for his kind critical review and suggestions concerning the manuscript.

\section{References}

1. Reddy VM, Liddicoat JR, Hanley FL. Midline one-stage complete unifocalization and repair of pulmonary atresia with ventricular septal defect and major aortopulmonary collaterals. J Thorac Cardiovasc Surg. 1995;109:832-45.

2. Tchervenkov CI, Salasidis G, Béland MJ, et al. One-stage midline unifocalization and complete repair in infancy versus multiple-stage unifocalization followed by repair for complex heart disease with major aortopulmonary collaterals. J Thorac Cardiovasc Surg. 1997; 114:727-37.
3. Reddy VM, McElhinney DB, Zahid A, et al. Early and intermediate outcomes after repair of pulmonary atresia with ventricular septal defect and major aortopulmonary collateral arteries: experience with 85 patients. Circulation. 2000;101:1826-32.

4. Rome JJ, Mayer JE, Castañeda AR, Lock YE. Tetralogy of Fallot with pulmonary atresia: rehabilitation of diminutive pulmonary arteries. Circulation. 1993;88:1691-8.

5. Nakata S, Imai Y, Takanashi Y, et al. A new method for the quantitative standardization of cross sectional areas of the pulmonary arteries in congenital arteries with decreased pulmonary blood flow. $J$ Thorac Cardiovasc Surg. 1984;88:610-9.

6. Liao P, Edwards WD, Julsrud PR, Puga FJ, Danielson GK, Feldt RH. Pulmonary blood supply in patients with pulmonary atresia and ventricular septal defect. J Am Coll Cardiol. 1985;6:1306-19.

7. Jefferson K, Rees S, Somerville J. Systemic arterial supply to the lungs in pulmonary atresia and its relationship to pulmonary artery development. Br Heart J. 1972;34:418-27.

8. Macartney FJ, Deverall PB, Scott O. Haemodynamic characteristics of systemic arterial blood supply to lungs. Br Heart J. 1973;35:28-37.

9. Macartney FJ. Haemodynamic and anatomical characteristics of pulmonary blood supply in pulmonary atresia and with ventricular septal defect including a case of persistent fifth aortic arch. Br Heart J. 1974;36:1049-60.

10. Haworth SG. Collateral arteries in pulmonary atresia with ventricular septal defect: a precarious blood supply. Br Heart J. 1980;44:513.

11. Haworth SG, Rees PG, Taylor JFN, Macartney FJ, de Leval M, Stark J. Pulmonary atresia with ventricular septal defect and major aortopulmonary collateral arteries: effect of systemic pulmonary anastomosis. Br Heart J. 1981;45:133-41.

12. Haworth SG, Macartney FJ. Growth and development of pulmonary circulation in pulmonary atresia with ventricular septal defect and major aortopulmonary collateral arteries. Br Heart J. 1980;44:1424.

13. Thiene G, Bortolotti U, Gallucci V, et al. Pulmonary atresia with ventricular septal defect: further anatomical observations. Br Heart J. 1977;39:1223-33.

14. Thiene G, Frescura C, Bini RM, et al. Histology of pulmonary arterial supply in pulmonary atresia with ventricular septal defect. Circulation. 1979;60:1066-74.

15. Thiene G, Frescura C, Bortolotti U, et al. The systemic pulmonary circulation in pulmonary atresia with ventricular septal defect: concept of reciprocal development of the fourth and sixth aortic arches. Am Heart J. 1981;101:339-44.

16. Rabinovitch M, Herrera-De Leon V, Castaneda AR, Reid L. Growth and development of the pulmonary vascular bed in patients with tetralogy of Fallot with or without pulmonary atresia. Circulation. 1981;64:1234-47.

17. Sullivan ID, Wren C, Stark J, de Leval MR, et al. Surgical unifocalization in the pulmonary atresia and ventricular septal defect: a realistic goal? Circulation. 1988;78(Suppl III):III-5-13.

18. Puga FJ, Leoni FE, Julsrud PR, Mair DD. Complete repair of pulmonary atresia, ventricular septal defect, and severe peripheral arborization abnormalities of the central pulmonary arteries: experience with preliminary unifocalization procedures in 38 patients. J Thorac Cardiovasc Surg. 1989;98:1018-29.

19. Iyer K, Mee RBB. Staged repair of PA with VSD and major systemic to pulmonary artery collaterals. Ann Thorac Surg. 1991;51:65-72.

20. Sawatari K, Imai Y, Kurosawa H, et al. Stage operation for pulmonary atresia and ventricular septal defect with major aortopulmonary collateral arteries: new technique for complete unifocalization. J Thorac Cardiovasc Surg. 1989;98:738-50.

21. Marelli AJ, Perloff JK, Child JS, Laks H. Pulmonary atresia with septal defect in adults. Circulation. 1994;89:243-51.

22. Yagihara T, Yamamoto F, Nishigaki K, et al. Unifocalization for pulmonary atresia with ventricular septal defect and major aortopulmonary collateral arteries. J Thorac Cardiovasc Surg. 1996;112:392402.

23. Doty DB, Kouchoukos NT, Kirklin JW, Barcia A, Bargeron LM. Surgery for pseudotruncus arteriosus with pulmonary blood flow from 
upper descending thoracic aorta. Circulation. 1972;45(Suppl I):I121-9.

24. Murphy DA, Sridhara KS, Nanton MA, Roy DL, Belcourt CL, Gillis DA. Surgical correction of pulmonary atresia with multiple large systemic pulmonary collaterals. Ann Thorac Surg. 1979;27: 460-4.

25. Carotti A, Di Donato R, Squitieri C, Guccione P, Catena G, Castaneda AR. Total repair of pulmonary atresia with ventricular septal defect and major aortopulmonary collaterals: an integrated approach. $J$ Thorac Cardiovasc Surg. 1998;116:914-23.

26. Castaneda AR, Jonas RA, Mayer JE Jr, Hanley FL. Developmental biology: respiratory system. In: Castaneda AR, Jonas RA, Mayer JE Jr, Hanley FL, editors. Cardiac surgery of the neonate and infant. Philadelphia: WB Saunders; 1994. p. 18-22.

27. Rabinovitch M. Pathobiology of the pulmonary hypertension: impact on clinical management. Seminars in thoracic and cardiovascular surgery. Pediatric cardiac surgery annual. Philadelphia: WB Saunders; 2000. p. 63-81.

28. Rees S, Somerville J. Aortography in Fallot's tetralogy and variants. Br Heart J. 1969;31:146-53.

29. Castaneda AR, Jonas RA, Mayer JE Jr, editors. Cardiac surgery of the neonate and infant. Philadelphia: WB Saunders; 1994. 